\title{
Editorial
}

\section{Innovation and debate: The way forward for brand management}

This is the first issue of The Journal of Brand Management and it will be interesting to monitor the response and reaction of readers to the Journal's contents.

There is a clear need for well-written papers from academics and practitioners that provide insight into this subject. The Journal makes its first appearance against a tough economic background, a changing definition of the practice of brand management, and more questions about the value and effectiveness of marketing investment than ever before.

The Journal will contain heated debates leading to divided opinion. That is a good thing: open discussions lead to a considered viewpoint. The industry should ask important questions relating to the role of brand managers, and the level of investment in marketing. Marketers will need to justify huge price premiums versus own label to the consumer.

At a Marketing Society Conference in March, 1993, the Chief Executive of United Biscuits, Eric Nicoli, warned brand managers to be careful, and to recognise the need to adapt and not to reminisce about the 'good old days'.

I believe strongly and passionately in brand marketing, having worked for Unilever and Cadbury Schweppes, two companies whose business has been successfully built on the strength of its brands. I have also seen and see today, that major changes are required. Premium brands with national advertising can only be carried by a company which innovates, updates quickly and constantly, and delivers adequate return for customers and manufacturers. In a recession consumers are more demanding, competitors are more likely to spring up and capture market share by using different economic criteria.

Brands are not the sole prerogative of multinational companies; they do not need national television advertising to be successful. Brand share can be built by using a variety of means, and the only losers will be those companies which take a traditional approach.

Marketing and brand management remains an exciting domain, and the industry will need to respond to many challenges. The Journal of Brand Management will provide academic debate, and responses to many questions. It will put brand management in the forefront of industry and, hopefully, provide the impetus for economic growth.

Tim Kelly Editorial Board 